\title{
SUPLEMENTAÇÃO COM FONTES PROTEICAS NA TERMINAÇÃO DE NOVILHAS DE CORTE: ESTUDO BIOECONÔMICO
}

\section{SUPPLEMENTATION WITH PROTEIN SOURCES IN THE FINISHING STAGE OF BEEF HEIFERS: A BIOECONOMICAL STUDY}

\author{
Rondineli Pavezzi Barbero ${ }^{1 *}$ \\ Marco Aurélio Alves de Freitas Barbosa ${ }^{1}$ \\ Ana Paula de Souza Fortaleza ${ }^{1}$ \\ Fernando Luiz Massaro Júnior ${ }^{1}$ \\ Leandro das Dores Ferreira da Silva ${ }^{1}$ \\ Letícia Maria de Castro $^{1}$ \\ ${ }^{1}$ Universidade Estadual de Londrina, Londrina, PR, Brasil \\ *Autor para correspondência - rondinelibarbero@zootecnista.com.br
}

\section{Resumo}

O objetivo deste trabalho foi avaliar biológica e economicamente a utilização de três fontes proteicas (farelo de soja (FS), caroço de algodão (CA) ou torta de nabo forrageiro (TN)), na formulação de suplementos $(1,0 \%$ do peso corporal (PC)) na terminação de novilhas de corte em pastos de capim Marandu na estação seca. Este experimento foi realizado no município de Potirendaba, SP, e análises químicas na Universidade Estadual de Londrina, PR. Aárea experimental foi de seis hectares, dividida em três piquetes, cada um com seis novilhas de corte $1 / 2$ sangue Simental, $1 / 2$ Nelore, PC inicial de $210 \pm 8,34 \mathrm{~kg}$, idade de $15 \pm 3$ meses. Foi realizada análise econômica utilizando-se método de orçamentos parciais. O delineamento experimental foi inteiramente casualizado, com seis repetições por tratamento $(n=18)$. Foi realizada análise de variância e as médias foram comparadas pelo teste Tukey $(\mathrm{P}<0,05)$. Animais suplementados com $\mathrm{TN}$ apresentaram menor ganho de peso ( $\mathrm{FS}=0,81$, $\mathrm{CA}=0,76$ e $\mathrm{TN}=0,40 \mathrm{~kg} /$ animal $/ \mathrm{dia} ; \mathrm{P}<0,05)$. Foi observada alteração negativa no rendimento líquido para os suplementos CA (US\$-22,15/animal) e TN (US\$-1,96/animal) em relação ao suplemento FS que, embora apresente maior valor de aquisição, mostrou-se favorável biológica e economicamente. Palavras-chave: gado de corte; orçamentos parciais; suplementação.

\begin{abstract}
The purpose of this study was to evaluate biological and economically the use of three protein sources (soybean meal (SM), cottonseed (CS) or turnip cake (TC)), in the supplement formulation (1.0\% of body weight $(\mathrm{BW})$ ) in the finishing stage of heifers grazing Marandu grass pastures during the dry season. This experiment was conducted in the city of Potirendaba, São Paulo State, and the chemical analyses were performed at the Londrina State University, Paraná State. The experimental area had six hectares, divided into three paddocks, each one with six crossbred heifers (Simmental $\times$ Nellore), initial BW of $210 \pm 8.34 \mathrm{~kg}$, and age of $15 \pm 3$ months. Economic analysis was performed using the method of partial budgeting. The experimental design was completely randomized, with six replicates per treatment $(n=18)$. Analysis of variance was conducted, and means were compared by Tukey test $(P<0.05)$. Animals supplemented with TC exhibited lower weight gain $(\mathrm{SM}=0.81, \mathrm{CS}=0.76$ and $\mathrm{TC}=0.40 \mathrm{~kg} /$ animal / day; $\mathrm{P}<0.05)$. Negative changes were observed in net income for the CS supplements (US \$ -22.15 / animal) and TC (US \$ -1.96 / animal) relative to the SM supplement,
\end{abstract}


which showed better biologic and economic results.

Keywords: beef cattle; partial budgets; supplementation.

Enviado em: 14 outubro de 2011

Aceito em: 15 dezembro de 2015

\section{Introdução}

As gramíneas forrageiras constituem a principal fonte de alimentos na produção de bovinos de corte no Brasil e algumas de suas características são a grande sazonalidade de produção ${ }^{(1)}$ e o fato de, em algumas épocas do ano, não suprirem os requerimentos nutricionais dos animais ${ }^{(2)}$. Isso leva à necessidade de se buscarem alternativas, como a suplementação, para que os animais atinjam ganhos de peso favoráveis ${ }^{(3)}$. Um fator importante é a possibilidade de se substituírem ingredientes de acordo com a disponibilidade e valor de mercado. Neste contexto, destaca-se o setor dos biocombustíveis com co-produtos como os farelos e tortas de algodão, soja ou nabo forrageiro ${ }^{(4)}$. A avaliação dos possíveis efeitos gerados pelos alimentos substituintes deve vir acompanhada de análise econômica, pois o aumento no desempenho e ganho de peso dos bovinos deve ser compatível com os investimentos ${ }^{(5)}$. A metodologia de orçamentos parciais permite detectar alterações no rendimento líquido quanto à alteração de um único e conhecido componente, por análise das diferenças de receitas e desembolsos gerados ${ }^{(6)}$. A literatura atual é escassa de trabalhos neste sentido, principalmente quanto ao uso de novos co-produtos gerados pela agroindústria. A hipótese deste estudo é a de que o uso de co-produtos na formulação de suplementos reduz os custos de produção, sem influenciar o desempenho animal e, consequentemente, melhora o resultado econômico. O objetivo deste trabalho foi avaliar o uso de três fontes proteicas: farelo de soja (FS), caroço de algodão (CA) e torta de nabo forrageiro (TN) na formulação de suplementos para novilhas de corte, terminadas em pastos de Brachiaria brizantha cv. marandu, sobre o ganho de peso médio diário (GMD), peso corporal (PC) final e aspectos econômicos.

\section{Material e Métodos}

O presente trabalho foi realizado em uma propriedade comercial, em Potirendaba, noroeste do Estado de São Paulo, a uma altitude média de 469 m, situada a $21^{\circ} 05^{\prime} 06^{\prime}$ "de latitude sul e $49^{\circ} 20^{\prime} 12^{\prime \prime}$ de longitude oeste. O período experimental foi de maio a agosto do ano de 2007, com pluviosidade total no período de $256 \mathrm{~mm}$, com mais de $70 \%$ no primeiro mês. As temperaturas médias máximas no período foram de $26,5^{\circ} \mathrm{C}$ e as mínimas de $13{ }^{\circ} \mathrm{C}$. As análises químicas foram realizadas no Laboratório de Análise de Alimentos e Nutrição Animal da Universidade Estadual de Londrina (UEL), em Londrina, Paraná.

A área experimental foi de seis hectares, dividida em três piquetes de igual tamanho, constituídos uniformemente de Brachiaria brizantha cv. marandu e vedados de pastejo por 30 dias antes do início do experimento. Visando eliminar a influência da possível variação de massa de forragem entre os piquetes, os animais foram mantidos em cada piquete por sete dias, sendo rotacionados, de forma a manter os tratamentos em sentido pré-estabelecido ${ }^{(7)}$. A altura média do pasto foi de $35,6 \pm 0,92$ $\mathrm{cm}$. Cada piquete era provido de bebedouro e cocho coberto (2,0 $\mathrm{m}$ de comprimento), com acesso bilateral, permitindo o consumo simultâneo do suplemento por todos os animais.

Foram utilizadas 18 novilhas $1 / 2$ sangue Simental $1 / 2$ Nelore, peso corporal (PC) médio inicial de $210 \pm 8,34 \mathrm{~kg}$ e idade média de $15 \pm 3$ meses, distribuídas ao acaso nos piquetes experimentais. Foram avaliados três suplementos, formulados com base nas deficiências nutricionais da forragem em relação ao requerimento para GMD de $0,7 \mathrm{~kg} / \mathrm{dia}^{(8)}$, diferindo pela fonte proteica: FS, CA e TN, fornecidos diariamente na dose de $1,0 \%$ do PC. As sobras do cocho foram pesadas diariamente para cálculo do consumo do suplemento pelo lote. Os suplementos eram isoprotéicos e apresentavam níveis energéticos semelhantes (Tabela 1). 
Tabela 1: Composição percentual químico-bromatológica da forragem, farelo de soja (FS), caroço de algodão (CA) e torta de nabo forrageiro (TN), e participação dos ingredientes nos suplementos experimentais

\begin{tabular}{lcccc}
\hline & Forragem & FS & CA & TN \\
\hline Composição química (\%) & & & & \\
Matéria seca & 23,6 & 89,1 & 90,8 & 92,4 \\
Proteína bruta & 5,2 & 25,2 & 25,2 & 25,2 \\
Nutrientes digestiveis totais & 46,6 & 77,1 & 77,5 & 82,1 \\
Matéria orgânica & 87,6 & 93,4 & 92,8 & 94,0 \\
Composição dos suplementos (\%) & & & & \\
Ureia & - & 2,0 & 2,0 & 2,0 \\
Mistura mineral & - & 3,2 & 3,2 & 3,2 \\
Fonte proteica & - & 23,2 & 74,9 & 33,7 \\
Milho triturado & - & 71,6 & 19,9 & 61,1 \\
\hline
\end{tabular}

Composição química base na matéria seca, exceto a própria matéria seca. Nutrientes digestíveis totais calculados conforme equações propostas por Detmann et al. (9).

Amostras da forragem foram colhidas utilizando-se a técnica da simulação manual de pastejo, observando-se as frações do extrato do dossel forrageiro consumida pelos animais, na quantidade de aproximadamente $500 \mathrm{~g}$ por piquete, pré-secas em estufa de circulação de ar forçado $\left( \pm 55^{\circ} \mathrm{C}\right)$ por 72 horas. Amostras dos ingredientes e dos suplementos foram coletadas para análise da composição química. As concentrações de matéria seca (MS), matéria orgânica (MO) e proteína bruta (PB) foram obtidas utilizando-se procedimentos e metodologias descritas por Silva \& Queiroz ${ }^{(10)}$.

O GMD foi calculado pela diferença entre o PC final e o PC inicial, em ambas as pesagens foi adotado jejum alimentar e hídrico (12 h), com pesagens intermediárias (28 dias) para ajuste da suplementação (\% PC) ${ }^{(11)}$. Ao final do período experimental, as novilhas foram abatidas em frigorífico comercial seguindo o fluxo normal do estabelecimento. Após o abate, as carcaças foram identificadas e pesadas para cálculo da remuneração por animal.

A avaliação econômica foi realizada com a metodologia de orçamentos parciais, utilizada por Canesin et al. ${ }^{(6)}$. Esta metodologia permite calcular a alteração no rendimento líquido (ARL), a partir de diferenças específicas nos custos e receitas, considerando-se um tratamento padrão que, neste experimento, foi o suplemento FS, por ser a fonte proteica padrão na formulação de suplementos. A ARL foi calculada utilizando-se a seguinte equação:

$$
A R L=(R A+R C)-(C A+R R),
$$

em que: $\mathrm{RA}=$ receitas adicionais; $\mathrm{RC}=$ redução nos custos; $\mathrm{CA}=$ custos adicionais; $\mathrm{RR}=$ redução nas receitas.

Para tal análise, foi considerado o consumo médio de suplemento multiplicado pelo custo por $\mathrm{kg}$ de suplemento (US\$ 0,28; US\$ 0,27 e US\$ 0,15/kg de suplemento FS, CA e TN, respectivamente; US\$ $1,00=\mathrm{R} \$ 1,96$, agosto/2007). As receitas foram obtidas com a comercialização dos animais para abate (US\$31,72/@, livre de impostos). Esta metodologia foi adotada devido às semelhanças entre os sistemas estudados, diferindo somente pela composição dos suplementos.

O delineamento experimental foi inteiramente casualizado, com três tratamentos e seis repetições por tratamento $(n=18)$. Foi realizada análise de variância e aplicado o teste Tukey $(\mathrm{P}<0,05)$, utilizando-se os procedimentos do Software $\mathrm{SAS}^{\circledR}$ (versão 9.0: 2004) para comparação das médias de ganho médio diário, peso corporal final e peso e rendimento de carcaça. Os resultados econômicos foram comparados utilizando-se metodologia de orçamentos parciais, na qual o suplemento FS foi considerado como referência, sem testes estatísticos. 


\section{Resultados e Discussão}

$\mathrm{Na}$ ocasião de fornecimento diário de suplemento, comumente eram observadas sobras no cocho das novilhas que receberam suplemento com $\mathrm{TN}$ como fonte proteica. $\mathrm{O}$ consumo médio observado dos suplementos FS e CA no período experimental foi de $2,24 \pm 0,02 \mathrm{~kg} /$ novilha/dia e do suplemento TN de $1,06 \pm 0,52 \mathrm{~kg} /$ novilha/dia, abaixo de $1,0 \%$ do PC, como considerado na ocasião de formulação para o desempenho predito. Em pesquisas desenvolvidas por Franco et al. ${ }^{(12)}$, suplementação na ordem de $1,0 \%$ do PC não causa malefícios às condições ruminais, além de ter sido a mesma dose utilizada nos demais suplementos do presente estudo.

Mello et al. ${ }^{(13)}$ também constataram limitação no consumo de TN por bovinos em pastejo. $\mathrm{O}$ fator de maior influencia na limitação do consumo pode estar relacionado à possível baixa palatabilidade deste alimento, explicando a rejeição do suplemento pelos animais. $\mathrm{O}$ consumo médio de torta de nabo forrageiro contido nos suplementos foi de $0,34 \mathrm{~kg} /$ animal $/$ dia, aproximadamente $0,1 \mathrm{~kg} / 100$ kg PC. O menor consumo sugere que a torta de nabo forrageiro pode ser incluída em rações ou suplementos como limitadora de consumo.

Em consequência do menor consumo de matéria seca de suplemento, a ingestão de PB e NDT também foi menor para os animais que receberam suplementação com TN, inferior ao que é sugerido pelo NRC ${ }^{(8)}$ para o GMD predito. Tal fato explica o menor ganho de peso (Tabela 02) apresentado neste tratamento em relação aos demais $(\mathrm{P}<0,05)$. Ainda que um dos principais objetivos das misturas minerais protéicas energéticas seja estimular o consumo dos pastos secos por meio do fornecimento de proteína e energia para a flora ruminal e não o atendimento dos requerimentos nutricionais dos animais ${ }^{(14,15)}$, menor ingestão de PB e NDT na estação seca pode limitar o consumo de forragem.

Em virtude do menor GMD, as novilhas que receberam suplementação com TN como fonte proteica apresentaram menor PC final $(\mathrm{P}<0,05)$; no entanto, não foram detectadas diferenças estatisticamente significativas no peso e rendimento de carcaça e a remuneração média por carcaça foi de US\$353 (FS), US\$ 341 (CA) e US\$ 312 (TN) (Tabela 2). Ainda que tenha apresentado remuneração por carcaça inferior aos demais tratamentos, novilhas que receberam suplementação contendo TN apresentaram menores desembolsos com suplementação. Este fato pode ser observado por duas razões: 1) menor custo de aquisição desta fonte proteica; e 2) menor consumo deste suplemento em relação aos demais ( $\pm 53 \%$ inferior).

Tabela 2: Resultados biológicos e econômicos da terminação de novilhas cruzadas (Simental $\times$ Nelore) com suplementação contendo fontes proteicas: farelo de soja (FS), caroço de algodão (CA) ou torta de nabo forrageiro (TN) em pastos de capim Marandu

\begin{tabular}{lcccc}
\hline \multirow{2}{*}{ Item } & \multicolumn{3}{c}{ Tratamento } & \multirow{2}{*}{ CV (\%) } \\
\cline { 2 - 4 } & FS & CA & TN & \\
\hline Resultados biológicos & & & & \\
GMD (kg/animal/dia) & $0,81^{\mathrm{a}}$ & $0,76^{\mathrm{a}}$ & $0,40^{\mathrm{b}}$ & 25,13 \\
Peso corporal final (kg) & $331,2^{\mathrm{a}}$ & $322,7^{\mathrm{a}}$ & $287,7^{\mathrm{b}}$ & 12,31 \\
Peso de carcaça (kg) & 167,8 & 161,4 & 148,6 & 11,53 \\
Resultados econômicos & & & & \\
DSP (US\$/animal) & 52,3 & 51,5 & 13,6 & - \\
RCC (US\$/animal) & 353 & 341 & 312 & - \\
ARL (US\$/animal) & 0,0 & $-22,1$ & $-2,9$ & - \\
\hline
\end{tabular}

Ganho médio diário (GMD), desembolso com suplementação no período (DSP), receitas com comercialização da carcaça (RCC), alteração no rendimento líquido (ARL). Análise econômica utilizando metodologia de orçamentos parciais ${ }^{(6)}$, adotando o suplemento FS como referência. US\$1,00 $=\mathrm{R} \$ 1,96$, agosto/2007. Médias seguidas de letras diferentes na mesma linha diferem estatisticamente pelo teste Tukey $(\mathrm{P}<0,05)$. 
O ganho de peso corporal no período foi de 122 (FS), 110 (CA) e $80 \mathrm{~kg}$ (TN). Considerando o rendimento médio de carcaça de 50\%, obteve-se um ganho de carcaça de 61,55 e $40 \mathrm{~kg}$, nos tratamentos FS, CA e TN, respectivamente. Com a cotação de US\$ 31,72/arroba (15 kg de carcaça), houve ganho de US\$ 128,55 (FS), US\$ 166,22 (CA) e US\$ 84,67 (TN) por novilha. Embora o suplemento TN apresente menor ganho econômico, é preciso lembrar que, devido ao baixo consumo e valor de aquisição, este tratamento demonstrou menor custo de produção (US\$ 0,17/kg PC) em relação aos demais tratamentos (US\$ $0,45 \pm 0,02 / \mathrm{kg}$ PC).

Foram observadas alterações no rendimento líquido pela metodologia de orçamentos parciais. Foi observada resposta negativa nos tratamentos CA (US\$ - 22,1/animal) e TN (US\$ -2,9/animal) em relação ao FS, devido ao elevado GMD apresentado por este tratamento. Embora tenha apresentado o menor GMD, o tratamento TN também apresentou o menor custo de produção, o que lhe conferiu posição intermediária na análise econômica. O valor do suplemento CA foi de $96 \%$ do valor do suplemento FS. O CA é um potencial substituto ao FS; no entanto, nas condições apresentadas neste trabalho, quando o custo de aquisição do CA for superior à $96 \%$ do FS, a escolha do FS deve ser priorizada.

\section{Conclusões}

Suplementos utilizando torta de nabo forrageiro como fonte proteica proporcionam ganho de peso na terminação de novilhas de corte inferior ao farelo de soja ou caroço de algodão. A relação entre o valor de suplementos contendo farelo de soja ou caroço de algodão deve ser considerada. Ainda que tenha apresentado maior valor de aquisição, o suplemento formulado com farelo de soja apresentou o melhor resultado biológico e econômico.

\section{Agradecimentos}

Os autores agradecem ao Sr. Odail Barbero e família, por não pouparem esforços e permitirem a realização deste trabalho em sua propriedade. Este trabalho também é dedicado à memória do Prof. Dr. Marco Aurélio Alves de Freitas Barbosa.

\section{Referências}

1. Silva SC, Nascimento Júnior D. Avanços na pesquisa com plantas forrageiras tropicais em pastagens: características morfofisiológicas e manejo do pastejo. Revista Brasileira de Zootecnia. 2007;36:122-138.

2. Zervoudakis JT, Paulino MF, Detmann E, Cabral LS, Valadares Filho SC, Moraes EHBK, Paula NF, Carvalho DMG. Suplementos múltiplos de autocontrole de consumo para recria de novilhos no período das águas: consumo de nutrientes e parâmetros ingestivos. Revista Brasileira de Saúde e Produção Animal. 2008;9(4):754-761.

3. El-Memari Neto AC, Zeoula LM, Cecato U, Prado IN, Caldas Neto, SF, Kazama R, Oliveira FCL. Suplementação de novilhos nelore em pastejo de Brachiaria brizantha com diferentes níveis e fontes de concentrado. Revista Brasileira de Zootecnia. 2003;32(6):1945-1955.

4. Fortaleza APS, Silva LDF, Ribeiro ELA, Barbero RP, Massaro Junior FL, Santos AX, Castro VS, Castro FAB. Degradabilidade ruminal in situ dos componentes nutritivos de alguns suplementos concentrados usados na alimentação de bovinos. Semina. 2009;30(2):471-486.

5. Campos Neto O, Scalzo AL, Fernandes VCG. Avaliação técnica e econômica da suplementação mineral, protéica e energética para bovinos da raça nelore em pastejo de $B$. Decumbens no período da seca. Revista Científica de Medicina Veterinária. 2004;2:32-35.

6. Canesin RC, Berchielli TT, Andrade P, Faturi C. Características da carcaça e da carne de novilhos mantidos em pastagem de capim-marandu submetidos a diferentes estratégias de suplementação. Revista Brasileira de Zootecnia. 2006;35(6):2368-2375.

7. Paulino MF, Moraes EHBK, Zervoudakis JT, Alexandrino E, Figueiredo DA. Terminação de novilhos 
mestiços leiteiros sob pastejo, no período das águas, recebendo suplementação com soja. Revista Brasileira de Zootecnia. 2006;35(1):154-158.

8. National Research Council. Nutrient Requirements of Beef Cattle. 7. ed., Washington: National Academy Press, 1996. 248p.

9. Detmann E, Valadares Filho SC, Pina DS, Henriques LT, Paulino MF, Magalhães KA, Silva PA, Chizzotti ML. Prediction of the energy value of cattle diets based on the chemical composition of the feeds under tropical conditions. Animal Feed Science and Technology. 2008;143:127-147.

10. Silva DJ, Queiroz AC. Análises de Alimentos (Métodos químicos e biológicos). Viçosa: Universidade Federal de Viçosa, 2002. 235p.

11. Ítavo LCV, Ítavo CCBF, Dias AM, Novais MFSM, Silva FF, Mateus RG, Schio AR. Desempenho produtivo e avaliação econômica de novilhos suplementados no períodoseco em pastagens diferidas, sob duas taxas de lotação. Revista Brasileira de Saúde e Produção Animal. 2007;8(3):229-238.

12. Franco GL, Barros LF, Rocha MST, Medeiros LQ, D'Oliveira MC, Diogo JMS, Ramos AKB. Suplementação proteico-energética sobre o consumo voluntário e parâmetros ruminais em novilhos. Revista Brasileira de Saúde Produção Animal. 2010; 11(2):371-385.

13. Mello DF, Franzolin R, Fernandes LB, Franco VM, Alves TC. Avaliação do resíduo de nabo forrageiro extraído da produção de biodiesel como suplemento para bovinos de corte em pastagens. Revista Brasileira de Saúde e Produção Animal. 2008; 9(1):45-56.

14. Frizzo A, Rocha MG, Restle J, Montagner DB, Freitas FK, Santos DT. Suplementação energética na recria de bezerras de corte mantidas em pastagem de inverno. Revista Brasileira de Zootecnia. 2003;32(3):643-652.

15. Silva RMG, Cabral LS, Abreu JG, Zervoudakis JT, Souza AL, Ochove VCC, Miranda L, Oliveira ÍS. Níveis de uréia em suplementos múltiplos para bovinos de corte durante a época seca. Revista Brasileira de Saúde e Produção Animal. 2008; 9(3):543-553. 